\title{
Inflorescence Development of the 'Hass' Avocado: Commitment to Flowering
}

\author{
Samuel Salazar-García, ${ }^{1}$ Elizabeth M. Lord, ${ }^{2}$ and Carol J. Lovatt ${ }^{3}$ \\ Department of Botany and Plant Sciences, University of California, Riverside, CA 92507-0124
}

\begin{abstract}
ADDitIONAL INDEX WORDs. flowering, inflorescence initiation, photoperiod, temperature, gibberellic acid, Persea americana
AbSTRACt. The developmental stage at which the shoot primary axis meristem(PAM) of the 'Hass' avocado(Persea americana Mill.) is committed to flowering was determined. Three-year-old trees were subjected to low-temperature (LT) treatments at 10/7 ${ }^{\circ} \mathrm{C}$ day/night with a 10-h photoperiod for 1 to 4 weeks followed by $25 / 20{ }^{\circ} \mathrm{C}$ day/night at the same photoperiod. Before LT treatment, apical buds of mature vegetative shoots consisted of a convex PAM with two lateral secondary axis inflorescence meristems lacking apical bracts each associated with an inflorescence bract. Apical buds did not change anatomically during LT treatment. However, the 3- and 4-week LT treatments resulted in inflorescences at $17 \%$ and $83 \%$ of apical buds, respectively. Trees receiving 2 weeks or less LT, including controls maintained at $25 / 20{ }^{\circ} \mathrm{C}$, produced only vegetative shoots. Apical buds of 2-year-old trees receiving 3 weeks at $10 / 7{ }^{\circ} \mathrm{C}$ plus 1 week at $20 / 15{ }^{\circ} \mathrm{C}$ produced $100 \%$ inflorescences. $\mathrm{GA}_{3}\left(100 \mathrm{mg} \cdot \mathrm{L}^{-1}\right)$ applied to buds 2 or 4 weeks after initiation of this $\mathrm{LT}$ treatment did not reduce the number of inflorescences that developed. 'Hass' avocado apical buds were fully committed to flowering after 4 weeks of LT, but were not distinguishable anatomically from those that were not committed to flowering.
\end{abstract}

During the developmental processes leading to commitment to flowering in a woody angiosperm, a vegetative shoot apex undergoes transition to a reproductive apex. For the 'Hass' avocado (Persea americana Mill.) the transition from the vegetative to reproductive condition occurs from the end of July through August on summer shoots (end of shoot expansion) (Salazar-García et al., 1998). The transition is followed by the initiation of bracts and their associated secondary axis inflorescence meristems from August to October, followed by anthesis 7 months later. A period of dormancy is not a prerequisite for transition to flowering or inflorescence development (Salazar-García et al., 1998).

Development of the avocado inflorescence is correlated with night temperature $\leq 15^{\circ} \mathrm{C}$, but whether low temperature plays a role in the transition, commitment or initiation of reproductive growth of the avocado is not known. At some point in the transition, which is apparently different for different species, the process is no longer reversible and the primary axis meristem (PAM) is committed to flowering (McDaniel, 1994). In the avocado, as in other adult woody angiosperms, only some apices flower; others continue the vegetative growth of the tree (Lord and Eckard, 1985). In order to manage vegetative and reproductive growth to improve avocado yield, it is critical to know when a PAM is irreversibly committed to be an inflorescence shoot. At present, due to the lack of experimental evidence, it is assumed that the PAM is fully committed to flowering when the two apical bracts are extended over the secondary axis inflorescence meristem, indicative of the initiation of the terminal

\footnotetext{
Received for publication 17 Aug. 1998. Accepted for publication 18 May 1999 This research was supported in part the Citrus Research Center and Agricultural Experiment Station of the Univ. of California, Riverside, and by the California Avocado Commission. This paper represents a portion of the dissertation submitted by S.S.-G. in partial fulfillment of requirements for a $\mathrm{PhD}$ in botany at the Univ. of California. The senior author acknowledges the financial support of CONACYT and INIFAP of Mexico and the University of California, Riverside. We thank Kathleen Eckard for her excellent technical advice and William Thomson and Claire E. Salem for their critical review of the manuscript. The cost of publishing this paper was defrayed in part by the payment of page charges. Under postal regulations, this paper therefore must be hereby marked advertisement solely to indicate this fact.

${ }^{1}$ Current address: INIFAP-Campo Experimental Santiago Ixcuintla, Apdo. Postal 100, Santiago Ixcuintla, NAY 63300, Mexico; to whom reprint requests should be addressed.

${ }^{2}$ Professor of plant development.

${ }^{3}$ Professor of plant physiology.
}

flower in the triplet (Thorp et al., 1994). This is a very late stage in the development of the avocado inflorescence (Salazar-García et al., 1998).

Gibberellic acid $\left(\mathrm{GA}_{3}\right)$ was used to determine the developmental stage associated with irreversible commitment to flowering of the navel orange (Citrus sinensis L.). When a winter prebloom application of $\mathrm{GA}_{3}$ was made to navel orange buds before they were committed to flowering, potential inflorescence shoots were diverted to vegetative shoots (Lord and Eckard, 1987). However, when $\mathrm{GA}_{3}$ was applied after formation of the first sepal of the apical flower of the Citrus cymose inflorescence, no diversion occurred. Sepal formation was associated with macroscopic (noticeable swelling of the bud and separation of the scale leaves) bud break in January in California. All GA 3 -treated navel orange buds developed normally. In contrast, winter prebloom (November to January) applications of $\mathrm{GA}_{3}$ to avocado branches stimulated all apical buds to start growing earlier than untreated buds (Salazar-García and Lovatt, 1998). Microscopic analysis revealed that in November there were significantly fewer buds in which all 10 secondary axis meristems of the inflorescence had formed compared to buds analyzed in December or January. $\mathrm{GA}_{3}\left(50 \mathrm{mg} \cdot \mathrm{L}^{-1}\right)$ applied in November stimulated early development of the partially and fully formed inflorescences; whereas $\mathrm{GA}_{3}$ at a higher concentration $\left(100 \mathrm{mg} \cdot \mathrm{L}^{-1}\right)$ diverted inflorescence buds to vegetative shoots. Application of $\mathrm{GA}_{3}$ $\left(1000 \mathrm{mg} \cdot \mathrm{L}^{-1}\right)$ in December or January did not affect the type of growth produced (vegetative or reproductive) by apical buds. Thus, in Persea as in Citrus, there is a point in the developmental process at which the PAM is committed to flowering and cannot be diverted to a vegetative shoot by $\mathrm{GA}_{3}$ treatment. To manage vegetative versus reproductive growth in a commercial avocado orchard, it is necessary to identify an anatomical change that marks the point in the flowering process before which the PAM can be diverted to vegetative growth by $\mathrm{GA}_{3}$ and after which the PAM is committed to flowering. With this marker, $\mathrm{GA}_{3}$ could be used effectively to reduce or eliminate alternate bearing.

Temperature is an additional factor known to inhibit or enhance floral initiation in avocado that can be used to help identify an anatomical change associated with commitment to flowering. Buttrose and Alexander (1978) and Nevin and Lovatt (1989) used as little as 4 weeks of low temperature (LT) treatment $\left(\leq 15^{\circ} \mathrm{C}\right)$ with 
Fig. 1. Diagram of an avocado shoot showing bud positions numbered basipetally.

daylength of $\leq 10 \mathrm{~h}$ to successfully cause flowering in 'Fuerte' and 'Hass' avocado, respectively. Trees maintained at 24 ${ }^{\circ} \mathrm{C}$ day/19 ${ }^{\circ} \mathrm{C}$ night and 12-h photoperiod (Nevin and Lovatt, 1989) or at a constant minimum temperature $>20^{\circ} \mathrm{C}$ did not produce inflorescences (Buttrose and Alexander, 1978). Daylength was without effect on the number of inflorescences produced in avocado, but shorter daylength $(\leq 10 \mathrm{~h})$

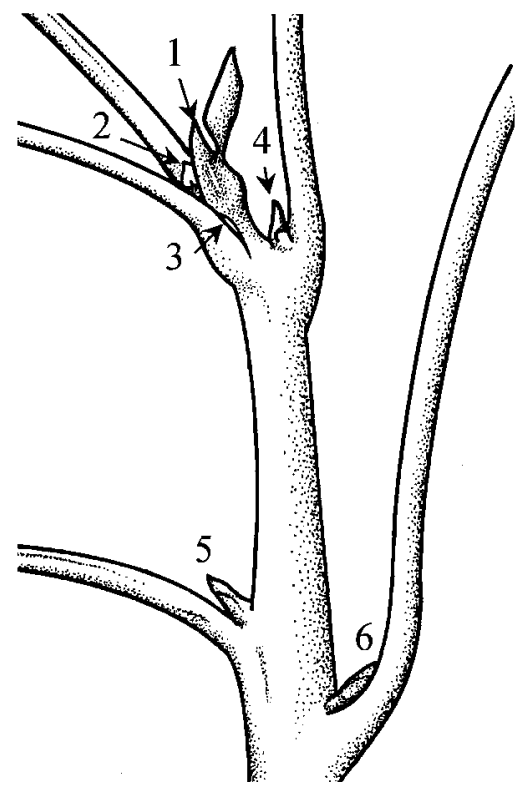
shortened the time to anthesis (Buttrose and Alexander, 1978). Subsequently, Jaganath (1993) observed that trees produced more inflorescences if the day and night temperatures were increased from $\leq 15^{\circ} \mathrm{C}$ to 20 and $15^{\circ} \mathrm{C}$, respectively, for $10 \mathrm{~d}$ before the temperature was increased to $25 / 20{ }^{\circ} \mathrm{C}$ day/night. Daylength did not affect inflorescence production.

In a previous paper, we documented the stages of inflorescence and flower development in the 'Hass' avocado (Salazar-García et al., 1998). Here, we report for the first time, the results of experiments conducted with adult 'Hass' avocado scions to determine the developmental stage at which the shoot PAM is irreversibly committed to flowering. Low temperature treatments were used to cause floral initiation and warm temperature or $\mathrm{GA}_{3}$ was used to stop or reverse the process. The objective was to identify an early anatomical change at the macro- or microscopic level before which the developmental fate of the PAM could be diverted to vegetative growth, but after which the PAM was irreversibly committed to flowering.

\section{Materials and Methods}

EFFECT OF TEMPERATURE ON COMMITMENT to FlOWERING. The research used 30 'Hass' avocado trees on Duke 7 clonal rootstock planted in 52-L plastic containers (diameter $38.1 \mathrm{~cm}$; height 45.7 $\mathrm{cm}$ ) filled with University of California Soil Mix III (Baker, 1957), amended with $0.15 \mathrm{~kg} \mathrm{KNO}_{3}, 0.15 \mathrm{~kg} \mathrm{~K}_{2} \mathrm{SO}_{4}, 2.23 \mathrm{~kg}$ dolomite, and $0.89 \mathrm{~kg}$ oyster-shell lime $/ \mathrm{m}^{3}$ medium. Trees were kept in a lath house at a maximum daily photosynthetic photon flux $(P P F)$ of $1000 \mu \mathrm{mol} \cdot \mathrm{m}^{-2} \cdot \mathrm{s}^{-1}$ and watered every other day with half-strength Hoagland's nutrient solution (Hoagland and Arnon, 1950). Three years after grafting, trees were pruned to leave three main branches just above the graft union. Trees were kept in the lath house until new shoots reached full elongation in March. In June, trees were moved into growth chambers (modified Percival PGW 108; $2.3 \times 1.5 \times 2.0$ $\mathrm{m}$; Percival, Boone, Iowa) for an additional 3 months at constant 25 ${ }^{\circ} \mathrm{C}$ with a 12-h photoperiod, conditions that do not result in flowering (Buttrose and Alexander, 1978; Chaikiattiyos et al., 1994). PPF was maintained at $500 \mu \mathrm{mol} \cdot \mathrm{m}^{-2} \cdot \mathrm{s}^{-1}$ at the top of the trees by lowering the platform bearing the pots as trees grew taller with 28 VHO 195-W fluorescent lamps and twelve $67 \mathrm{~W}$ incandescent bulbs. Relative humidity was not controlled and ranged from $25 \%$ (night) to $75 \%$ (day).

In each of six growth chambers, five individual trees were subjected to LT treatments at $10 / 7^{\circ} \mathrm{C}$ (10-h day/14-h night) for 1,2 , 3 , or 4 weeks. This LT treatment when applied for 4 weeks is known to cause flowering of avocado (Nevin and Lovatt, 1989), whether treatment of shorter duration causes flowering is unknown. The LT treatment at $10 / 7{ }^{\circ} \mathrm{C}$ day/night (10-h photoperiod) for 4 weeks followed by 5 weeks at $20 / 15^{\circ} \mathrm{C}$, which further enhances flowering (Jaganath, 1993), was in the fifth chamber. At the end of each treatment, trees continued with the same photoperiod but temperature was increased to $25 / 20^{\circ} \mathrm{C}$ day/night (nonpromotive temperature regime) until trees that flowered reached anthesis, which marked the end of the experiment (a total of 19 weeks). Control trees were maintained in a sixth growth chamber at $25 / 20^{\circ} \mathrm{C}$ and a $10-\mathrm{h}$ photoperiod during the 19 weeks.

At the beginning of LT treatments, shoots had an average of 11 fully expanded leaves. For microscopic analysis, the apical bud at position 1 (Fig. 1) of one shoot per tree was collected at time zero and at the end of each temperature treatment (week 1, 2, 3, and 4 of LT). Buds were fixed in FAA ( 5 formalin : 5 acetic acid : 90 ethanol solution, by volume), dehydrated via sequential transfer through a series of aqueous ethanol solutions $(70 \%, 85 \%$, and $95 \%$ ethanol), and infiltrated and embedded in glycol methacrylate (Leica 702218500 Historesin, Leica Instruments $\mathrm{GmbH}, \mathrm{NuBloch} /$ Heidelberg). Infiltration was done in a graded Historesin:ethanol (95\%) series of 25:75 (by volume) (two changes in $24 \mathrm{~h}$ ), 50:50 and 75:25 (24 h each), and 100:0 (one change at $24 \mathrm{~h}$ and then left for $5 \mathrm{~d}$ ). Embedding in Historesin was done according to the manufacturer's instructions. Buds were serially sectioned longitudinally on a H/I Bright '5030' rotary microtome at $6 \mu \mathrm{m}$, mounted in water on glass slides, heated until dry, stained by flooding in $0.05 \%$ toluidine blue (O’Brien and McCully, 1981), and photographed with Kodak Technical Pan 2415 film on a Zeiss compound microscope. All bud sections were observed for presence of inflorescence meristems. The type of growth produced by apical buds in response to temperature treatments was quantified on 15 tagged mature shoots per tree at the end of the experiment, when most trees that flowered had reached anthesis (week 19).

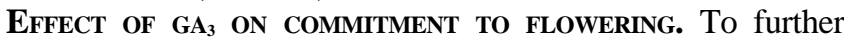
investigate the time at which the PAM of the 'Hass' avocado was fully committed to flowering, 20 'Hass' avocado trees on Duke 7 clonal rootstock, 2 years after grafting, were grown in 52-L containers (described above) in a lath house. Maximum and minimum air temperatures fluctuated between 32 and $16^{\circ} \mathrm{C}$ during the 12 summer weeks before the initiation of treatments. For each of the five trees per treatment, the apical (position 1) and axillary bud borne in the axil of the leaf in position 3 (Fig. 1) on each of five, 5-month-old mature shoots were tagged.

To induce floral initiation, trees were moved to growth chambers (described above; five trees per chamber) and subjected to LT treatment of $10 / 7^{\circ} \mathrm{C}$ day/night with a short (8-h) photoperiod for 3 weeks followed by 1 week at $20 / 15^{\circ} \mathrm{C}$ (transitional temperature), keeping the same daylength $\left(P P F=500 \mu \mathrm{mol} \cdot \mathrm{m}^{-2} \cdot \mathrm{s}^{-1}\right)$. At the end of the fourth week, trees were transferred and maintained in a glasshouse for 20 weeks, in which air temperature oscillated between 28 and $20^{\circ} \mathrm{C}$. Natural daylength was 10 to $11 \mathrm{~h}(P P F=670$ $\left.\mu \mathrm{mol} \cdot \mathrm{m}^{-2} \cdot \mathrm{s}^{-1}\right)$.

As done by Lord and Eckard (1987) in citrus, GA 3 (KC Biological, Inc., Kansas City, Kan.) at $100 \mathrm{mg} \cdot \mathrm{L}^{-1}$ (previously dissolved in 2 drops of ethanol $95 \%$ ) plus $50 \mathrm{mg} \cdot \mathrm{L}^{-1}$ Triton X-100 (Sigma Chemicals, St. Louis, Mo.) in distilled water was daubed (pH 
solution =4) with a cotton swab onto the apical and axillary (position 3) bud. $\mathrm{GA}_{3}$ was applied once to a separate set of five trees at the end of the second or fourth week of the 4-week LT treatment or 2 weeks after the end of the LT treatment (week 6). Buds of control trees were treated with water plus Triton X-100.

The apical bud at position 1 and axillary bud at position 3 (Fig. 1) from one shoot per tree were collected at time zero and on the day $\mathrm{GA}_{3}$ was applied. Buds were fixed and processed as described above. Axillary buds were serially sectioned longitudinally in an abaxial to adaxial direction (towards the main axis).

The effect of $\mathrm{GA}_{3}$ application time on the type of growth (reproductive or vegetative) produced by the tagged buds was determined 24 weeks after the initiation of the LT treatment; this was 20 weeks after trees were transferred to the glasshouse and had reached full bloom. Inflorescences were distinguished as determinate (PAM developed into a terminal flower) and indeterminate (PAM developed into a vegetative shoot after production of an inflorescence).

Twenty-four weeks after the initiation of the LT treatment, it was determined whether axillary buds had failed to grow due to inhibition by $\mathrm{GA}_{3}$ or by growth of the vegetative shoot of the apical indeterminate inflorescence borne at the apex. For all treatments, the terminal portion of a shoot was cut off, leaving position 3 axillary buds as leaders. Nine weeks later the effect of pruning was quantified.

EXPERIMENTAL DESIGN AND STATISTICAL ANALYSIS. A chamber with five single-tree replications per treatment was used in both studies. Data expressed as percentage were transformed by arcsin of the square root of the observation (Steel and Torrie, 1980). Means comparison was performed by Duncan's multiple range test at $P=$ 0.01 .

\section{Results}

EFFECT OF TEMPERATURE ON COMMITMENT TO FLOWERING. Control trees and trees receiving 1 or 2 weeks of LT treatment did not become reproductive; all growth was vegetative (Table 1). For the 3-week LT treatment, $17 \%$ of apical buds produced inflorescences, whereas $69 \%$ produced vegetative shoots. Shoot apical buds of trees treated for 4 weeks at $10 / 7{ }^{\circ} \mathrm{C}$ day/night produced $83 \%$ inflorescences and no vegetative growth; the remaining buds were inactive (a bud that did not produce either a vegetative shoot or inflorescence within the length of the experiment). Trees receiving 4 weeks at 10/ $7^{\circ} \mathrm{C}$ followed by 4 weeks of intermediate temperatures $\left(20 / 15^{\circ} \mathrm{C}\right)$ before transfer to $25 / 20^{\circ} \mathrm{C}$ produced inflorescences in $95 \%$ of the apical buds.
Anatomical sections of the apical buds at time zero revealed a convex PAM that had produced a secondary axis inflorescence meristem in the axil of each of two inflorescence bracts (one shown in Fig. 2A). At this time the secondary axis inflorescence meristems did not have apical bracts. Basal to the two secondary inflorescence bracts was up to four lateral shoots with leaflike bracts in the axils of bud scales (not shown). During the 4 weeks of exposure to lowtemperature, no anatomical changes were observed in the primary axis meristem (Fig. 2B) or in the four basal lateral shoots, despite the different effects of the length of the LT treatment on the developmental fate of the apical bud. Macroscopic analysis of apical buds at the beginning and end of the LT treatments revealed that the buds had not visibly changed and remained pointed with closed scales. Thus, we found no anatomical differences between buds committed to flowering and those that were not.

EFFECT OF GA $_{3}$ ON COMMITMENT TO FLOWERING. GA $\mathrm{G}_{3}$ applied to the apical buds during or after LT treatment did not affect the number of inflorescences produced, the production of vegetative shoots, or the number of inactive or abscised buds (data not shown). Production of inflorescences in all treatments ranged from $92 \%$ to $100 \%$ of the buds tagged at time zero.

Similar to the apical buds, $\mathrm{GA}_{3}$ applied to axillary buds (position 3 ) as early as the second week of LT treatment had no effect on the number of inflorescences that developed. However, a wide variation in the number of inflorescences produced was observed, ranging from $70 \%$ of the total buds in the untreated control to $35 \%$ for trees receiving $\mathrm{GA}_{3}$ at the end of week 4 of LT treatment. A decrease in inflorescence number was associated with a higher proportion of inactive buds ( $26 \%$ to $65 \%$ ). In week 24 , the fate of the inactive position 3 axillary buds in all treatments was determined by pruning off the terminal shoot, which left the position 3 axillary buds as leaders. Nine weeks after pruning, $75 \%$ of the axillary buds produced inflorescences; the remaining $25 \%$ were still inactive. This demonstrated that with or without $\mathrm{GA}_{3}$ treatment the majority of axillary buds were committed to flowering, but their development was suppressed by growth of the vegetative shoot of the apical inflorescences.

Control trees not treated with $\mathrm{GA}_{3}$ produced predominantly indeterminate inflorescences; $87 \%$ and $60 \%$ of the total inflorescences produced by apical and axillary buds, respectively. $\mathrm{GA}_{3}$ treatments did not alter the proportion of indeterminate to determinate inflorescences produced or the number of secondary axes per inflorescence produced by apical or axillary buds (data not shown). $\mathrm{GA}_{3}$ applications slowed early development of the inflorescence compared to the control, but had no effect on the time of anthesis.

Apical and position 3 axillary buds were analyzed at both the

Table 1. Effect of the duration of the low-temperature treatment $\left(10 / 7^{\circ} \mathrm{C}\right.$, day/night) on the type of growth produced by apical buds (position 1$)$ of mature shoots of 'Hass' avocado trees.

\begin{tabular}{|c|c|c|c|}
\hline \multirow[b]{2}{*}{$\begin{array}{l}\text { Duration of } 10 / 7{ }^{\circ} \mathrm{C} \text { treatment } \\
\text { before transfer to } 25 / 20^{\circ} \mathrm{C} \text { (weeks) }\end{array}$} & \multicolumn{3}{|c|}{$\begin{array}{c}\text { Type of growth } \\
(\% \text { buds tagged at time zero })^{\mathrm{z}}\end{array}$} \\
\hline & Inflorescence & $\begin{array}{l}\text { Vegetative } \\
\text { shoot }\end{array}$ & $\begin{array}{l}\text { Inactive } \\
\text { bud }\end{array}$ \\
\hline None-control (19 weeks at $\left.25 / 20^{\circ} \mathrm{C}\right)$ & $0 \mathrm{~b}^{\mathrm{y}}$ & $100 \mathrm{a}$ & $0 \mathrm{bc}$ \\
\hline 1 & $0 \mathrm{~b}$ & $93 \mathrm{a}$ & $7 \mathrm{ab}$ \\
\hline 2 & $0 \mathrm{~b}$ & $97 \mathrm{a}$ & $3 \mathrm{abc}$ \\
\hline 3 & $17 \mathrm{~b}$ & $69 \mathrm{~b}$ & $14 \mathrm{a}$ \\
\hline 4 & $83 \mathrm{a}$ & $0 \mathrm{c}$ & $13 \mathrm{a}$ \\
\hline $4+4$ weeks at $20 / 15^{\circ} \mathrm{C}$ & $95 \mathrm{a}$ & $0 \mathrm{c}$ & $5 \mathrm{ab}$ \\
\hline
\end{tabular}

${ }^{\mathrm{z}}$ Statistical analyses were performed on data transformed by arcsin of the square root of the observation.

yMean separation in columns by Duncan's multiple range test, $P=0.01$. 


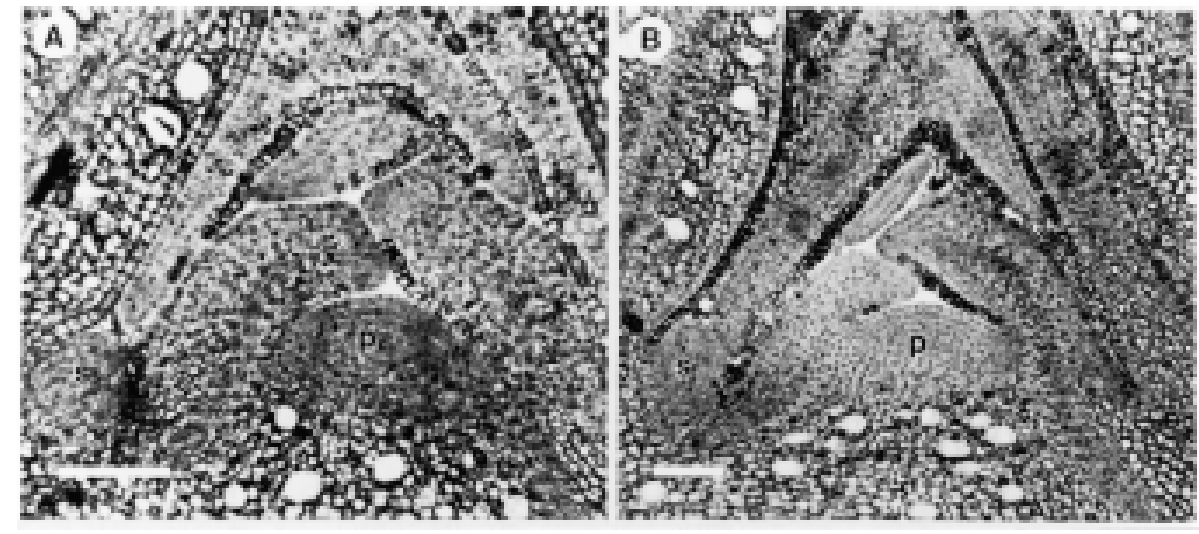

After 2 weeks of LT, all buds remained pointed with closed scales and no macroscopic sign of growth. However, $80 \%$ of position 3 axillary buds had now developed secondary axis inflorescence meristems (with no apical bracts) within the axils of one $(40 \%)$ or both $(40 \%)$ inflorescence bracts. After 4 weeks of LT treatment, all axillary buds had produced two secondary axis inflorescence meristems lacking apical bracts (Fig. 3B). Macroscopically all buds were still pointed with closed scales and no external sign of growth.

Two weeks after the trees were transferred from the LT treatment to the glass-

Fig. 2. Median longitudinal sections of apical (position 1) buds of 'Hass' avocado trees (experiment 1). (A) Apical bud with convex primary axis meristem and two secondary axis inflorescence meristems (one in view) at time zero. (B) Apical bud showing no anatomical changes after 4 weeks at $10 / 7{ }^{\circ} \mathrm{C}$. Abbreviations: $\mathrm{p}=$ primary axis meristem; $\mathrm{s}=$ secondary axis inflorescence meristem. Bars $=100 \mu \mathrm{m}$

house, partial senescence of the outermost bud scales of apical buds was observed. This was the first macroscopic sign of inflorescence bud development. It was associated at the microscopic level with elongation of the two secondary axis inflorescence meristems; apical bracts were still not present. About six secondary axis inflorescence meristems were present before the basal (most advanced) ones began to form apical bracts. This occurred before the bud scales separated. For apical buds, this was $\approx 4$ weeks after the end of LT (not shown).

\section{Discussion}

Consistent with the results of Buttrose and Alexander (1978) and Nevin and Lovatt (1989), low temperature and short daylength (8- to 10-h day) effectively caused flowering of the 'Hass' avocado. Four weeks at $10 / 7^{\circ} \mathrm{C}$ (10-h day/14-h night) were sufficient for apical buds of the 'Hass' avocado to become

Fig. 3. Median longitudinal sections of axillary (position 3) buds of 'Hass' avocado trees (experiment 2). (A) Axillary bud with convex primary axis meristem and no secondary axis inflorescence meristems at time zero. (B) Axillary bud with two secondary axis inflorescence meristems present at the end of 3 weeks at $10 / 7{ }^{\circ} \mathrm{C}$ followed by 1 week at $20 / 15^{\circ} \mathrm{C}$. Abbreviations: $\mathrm{p}=$ primary axis meristem; $\mathrm{s}=$ secondary axis inflorescence meristem. Bars $=100$ $\mu \mathrm{m}$.

macro- and microscopic level during the LT treatment to determine their stage of development at the time of $\mathrm{GA}_{3}$ treatment and transfer of the trees to warm temperature at the end of week 4 . At time zero, apical and axillary buds were pointed with closed scales. Microscopic examination of the apical buds confirmed that they were at the same anatomical stage reported in the temperature experiment above. The PAM was convex. Two inflorescence bracts, each with a secondary axis inflorescence meristem without apical bracts, were present. Lateral shoots had formed in the axils of the bud scales (not shown). As in the temperature experiment above, no anatomical changes were observed after 2 or 4 weeks of LT treatment. At time zero, position 3 axillary buds also had a convex PAM with two inflorescence bracts. In contrast to bracts of the apical buds, inflorescence bracts of axillary buds lacked secondary axis inflorescence meristems, although a mass of cells was visible in the axil of one inflorescence bract (Fig. 3A) at the initiation of LT treatment. Also absent in the axillary buds were the lateral shoots associated with the bud scales of apical buds at the start of LT treatment (not shown). fully committed to flowering. Apical buds from this treatment produced $83 \%$ inflorescences despite transfer to $25 / 20{ }^{\circ} \mathrm{C}$, a temperature that resulted in $100 \%$ vegetative shoots for trees that were maintained constantly at this temperature regime. In the second experiment, all trees received 3 weeks at $10 / 7{ }^{\circ} \mathrm{C}(8-\mathrm{h}$ day/16-h night) followed by 1 week at $20 / 15^{\circ} \mathrm{C}$ (8-h day/16-h night). Apical buds of control trees (those not treated with $\mathrm{GA}_{3}$ ) produced $100 \%$ inflorescences. Anatomically all apical buds were identical at the microscopic level before, during, and after the 4-week LT treatments. We detected no anatomical differences between apical buds committed to flowering and those that were not.

Axillary buds on a mature vegetative shoot were less developed than the apical bud. At the start of the LT treatment, axillary buds bore no secondary axis inflorescence meristems in the axils of their inflorescence bracts, whereas apical buds had two (apical bracts were absent). After 4 weeks of LT treatment, axillary buds had produced one pair of secondary axis inflorescence meristems (with no apical bracts). Thus, after 4 weeks of LT treatment, axillary buds had caught up with apical buds both anatomically and developmentally since axillary buds were also committed to flowering at this time. Hence, based on their anatomy, it is possible to distinguish axillary buds that are fully committed to flowering from those that are not by the presence or absence of a single pair of secondary axis inflorescence meristems (no apical bracts).

The results obtained by applying $\mathrm{GA}_{3}\left(100 \mathrm{mg} \cdot \mathrm{L}^{-1}\right)$ to avocado buds were not as striking as the results of the temperature experi- 
ment. In the present study $\mathrm{GA}_{3}$ application caused a delay in the early development of the inflorescence with no subsequent effect on time of anthesis compared to the untreated control trees. Thus, $\mathrm{GA}_{3}$ was clearly having a physiological effect on the PAM and was thus effectively able to penetrate the bud scales. Previously, this effect of $\mathrm{GA}_{3}$ on avocado inflorescence development has been observed only with the use of high concentrations of $\mathrm{GA}_{3}(2.5 \mathrm{~g} / \mathrm{tree})$ injected directly into the trunk of mature 'Hass' avocado trees (SalazarGarcía and Lovatt, 1999). Lower concentrations of GA $\mathrm{GA}_{3}$ injected (25 $\left.\mathrm{mg} \cdot \mathrm{L}^{-1}\right)$ into young trees or sprayed $\left(50 \mathrm{mg} \cdot \mathrm{L}^{-1}\right)$ on branches or entire mature trees consistently resulted in a more advanced rate of inflorescence development with no subsequent effect on the time of anthesis (Salazar-García and Lovatt, 1998, 1999). Whether lower or higher $\mathrm{GA}_{3}$ concentrations would have provided results as dramatic as transferring the trees to warm temperature after week 2 remains to be determined.

Jaganath (1993) previously observed that avocado trees transferred from day/night temperatures of $10 / 7^{\circ} \mathrm{C}$ to intermediate day/ night temperatures of $20 / 15^{\circ} \mathrm{C}$ for $10 \mathrm{~d}$ before they were treated with day/night temperatures of $25 / 20^{\circ} \mathrm{C}$ produced more floral buds than trees that were not transferred to the intermediate temperature regime. The results of the present study confirm that day/night temperatures of $20 / 15^{\circ} \mathrm{C}$ enhanced the effect of the lower temperature treatment. In the first experiment, apical buds of trees receiving 3 weeks at $10 / 7^{\circ} \mathrm{C}$ followed by direct transfer to $25 / 20^{\circ} \mathrm{C}$ produced $17 \%$ inflorescences and $69 \%$ vegetative shoots. In the second experiment, trees that received 3 weeks at $10 / 7^{\circ} \mathrm{C}$ followed by 1 week at $20 / 15^{\circ} \mathrm{C}$ produced $100 \%$ inflorescences. Thus, the temperature regime of $20 / 15{ }^{\circ} \mathrm{C}$ clearly had a positive effect on flowering. Control trees maintained at warm temperature $\left(25 / 20^{\circ} \mathrm{C}\right)$ and a short (10-h) photoperiod did not flower.

The results of this research are consistent with the hypothesis that the PAM transitions from vegetative to reproductive growth in a predictable pattern (Venning and Lincoln, 1958; SalazarGarcía et al., 1998). In a previous study, Salazar-García et al. (1998) found that a convex PAM is indicative of an active apex, producing either leaf primordia or inflorescence bracts. Secondary axis inflorescence meristems form in the axils of inflorescence bracts just below the PAM, as observed in the present study. As reported for other species (Bernier et al., 1981), flowering in avocado is not obligatory at this point. Thus, under environmental conditions that favor vegetative growth, or do not support reproductive growth, the PAM remains vegetative and subsequent development of secondary axis inflorescence meristems is repressed by the initiation of leaf primordia. In the present study, when LT treatment was <4 weeks, vegetative growth prevailed. Whereas 4 weeks at $10 / 7{ }^{\circ} \mathrm{C}$ or 4 weeks at $10 / 7^{\circ} \mathrm{C}+4$ weeks at $20 / 15^{\circ} \mathrm{C}$ were sufficient to repress vegetative growth and allow flowering to be fully expressed. At the time the PAM was committed to flowering, apical bracts were not yet present on the oldest secondary axis inflorescence meristems of either apical or axillary buds. The present study identified the stage of avocado inflorescence development associated with full commitment to flowering. The results establish that commitment to flowering is earlier than previously proposed on the basis of the presence of two apical bracts on the secondary axis inflorescence meristem (Thorp et al., 1994). In the present study, secondary axis inflorescence meristems were still at a primordial stage of development when the PAM was fully committed to flowering. Apical bracts did not form on the oldest secondary axis inflorescence meristems until four additional secondary axis inflorescence meristems had developed. For apical buds, this was $\approx 4$ weeks after the end of the
LT treatment. For axillary buds we demonstrated that secondary axis meristems in the axils of inflorescence bracts were absent (Fig. 3A) until the buds were committed to flowering. Thus, anatomical analysis of axillary buds would make it possible to identify when commitment to flowering occurred on a shoot earlier than would be possible by analysis of apical buds. The presence of three or more secondary axis inflorescence meristems should prove a useful anatomical marker for identifying a PAM that is committed to flowering. Partial senescence of the outermost bud scales of apical buds is associated with this stage of inflorescence development (Salazar-García, et al, 1998) and could be used in a commercial avocado orchard to distinguish buds that have fully committed to flowering from those that are not.

\section{Literature Cited}

Baker, K.F. 1957. University of California soil mixes. Calif. Agr. Expt. Sta. Manual No. 23.

Bernier, G., J.M. Kinet, and R.M. Sachs. 1981. The physiology of flowering. vol. II. Transition to reproductive growth. p. 21-34. CRC Press, Boca Raton, Fla.

Buttrose, M.S. and D.M. Alexander. 1978. Promotion of floral initiation in 'Fuerte' avocado by low temperature and short daylength. Scientia Hort. 8:213-217.

Chaikiattiyos, S., C.M. Menzel, and T.S. Rasmussen. 1994. Floral induction in tropical fruit trees: Effects of temperature and water supply. J. Hort. Sci. 69:397-415.

Hoagland, D.R. and D.I. Arnon. 1950. The water culture for growing plants without soil. Calif. Agr. Expt. Sta. Circ. 347 (revised).

Jaganath, I. 1993. Effect of boron and/or nitrogen on pollen tube growth, ovule viability and yield in 'Hass' avocado. MS thesis, Univ. Calif., Riverside.

Lord, E.M. and K.J. Eckard. 1985. Shoot development in Citrus sinensis L. (Washington navel orange). I. Floral and inflorescence ontogeny. Bot. Gaz. 146:320-326.

Lord, E.M. and K.J. Eckard. 1987. Shoot development in Citrus sinensis L. (Washington navel orange). II. Alteration of developmental fate of flowering shoots after GA treatment. Bot. Gaz. 148:17-22.

McDaniel, C.N. 1994. Photoperiodic induction, evocation and floral initiation, p. 25-43. In: R.L. Greyson (ed.). The development of flowers. Oxford Univ. Press, Oxford, U.K.

Nevin, J.M. and C.J. Lovatt. 1989. Changes in starch and ammonia metabolism during low temperature stress-induced flowering in Hass avocado-A preliminary report. S. Afr. Avo. Grow. Assn. Yrbk. 12:21-25.

O'Brien, T.P. and M.E. McCully. 1981. The study of plant structure: Principles and methods. Termarcarphi Pty Ltd. Melbourne, Australia. Salazar-García, S. and C.J. Lovatt. 1998. GA application alters flowering phenology of the 'Hass' avocado. J. Amer. Soc. Hort. Sci. 123:791797.

Salazar-García, S. and C.J. Lovatt. 1999. Winter trunk injections of gibberellic acid $_{3}$ altered the fate of 'Hass' avocado buds: Effects on inflorescence type, number and rate of development. J. Hort. Sci. Biotechnol. 73:69-73.

Salazar-García, S., E.M. Lord, and C.J. Lovatt. 1998. Inflorescence and flower development of the 'Hass' avocado (Persea americana Mill.) during "on" and "off" crop years. J. Amer. Soc. Hort. Sci. 123:537544.

Steel, R.G.D. and J.H. Torrie. 1980. Principles and procedures of statistics, a biometrical approach. 2nd ed. McGraw-Hill, Inc.

Thorp, T.G., D. Aspinall, and M. Sedgley. 1994. Preformation of node number in vegetative and reproductive proleptic shoot modules of Persea (Lauraceae). Ann. Bot. 73:13-22.

Venning, F.O. and F.B. Lincoln. 1958. Developmental morphology of the vegetative axis of avocado (Persea americana L.) and its significance to spacing, pruning practices, and yields of the grove. Proc. Fla. Sta. Hort. Soc. 71:350-356. 